\title{
Studies on organoleptic attributes and cost analysis of soy ice-cream
}

\section{J.DAVID}

\begin{abstract}
With the current upward trend in nutritional and health awareness, the consumer demand is for high nutritive valuable product in the market with acceptable sensory characteristics. The present study was undertaken with different levels $(10 \%, 20 \%$ and $30 \%)$ of soymilk used in ice cream preparation. Different samples of soy ice cream treatments and control were analyzed for fat, lactic acid, total solids, protein, ash and organoleptic characteristics (flavour and taste, body and texture, colour and appearance, overall acceptability). The data obtained on various parameters were statistically analyzed. It was observed that the soy ice cream prepared with 20 per cent $\left(\mathrm{T}_{2}\right)$ soymilk was highly acceptable in terms of flavour and taste, texture and overall acceptability as compared to the other experimental treatment combination.
\end{abstract}

KEY WORDS : Ice cream, Soymilk,Organoleptic attributes, Cost analysis

HOW TO CITE THIS PAPER : David, J. (2016). Studies on organoleptic attributes and cost analysis of soy ice-cream. Res. J. Animal Hus. \& Dairy Sci., 7(1) : 7-10 : DOI: 10.15740/HAS/RJAHDS/7.1/7-10.

J. David, Department of Dairy Technology, Sam Higginbottom Institute of Agriculture, Technology and Sciences, ALLAHABAD (U.P.) INDIA

Email : profjohndavid06@gmail.com 